\title{
Ignition, puffing and sooting characteristics of kerosene droplet combustion under sub-atmospheric pressure
}

\author{
Hongtao Zhang ${ }^{\mathrm{a}}$, Zhihua Wang, ${ }^{\mathrm{a}, *}$, Yong $\mathrm{He}^{\mathrm{a}}$, Jun Xia ${ }^{\mathrm{b}}$, Jincheng Zhang ${ }^{\mathrm{a}}$, Hua \\ Zhao $^{\mathrm{b}}$, Kefa Cen ${ }^{\mathrm{a}}$ \\ ${ }^{a}$ State Key Laboratory of Clean Energy Utilization, Zhejiang University, Hangzhou 310027, \\ P.R. China \\ ${ }^{b}$ Department of Mechanical and Aerospace Engineering $\&$ Institute of Energy Futures, \\ Brunel University London, Uxbridge UB8 3PH, U.K.
}

\begin{abstract}
The ignition, puffing and sooting characteristics of Chinese RP-3 kerosene droplet burning have been studied using high-speed, $\mathrm{OH}^{*}$ chemiluminescence and soot thermal radiation imaging. The experiments were conducted in air at standard temperature and sub-atmospheric pressures ranging from 0.2 bar to 1 bar. The kerosene droplet was supported by a thermocouple tip and ignited by a retractable coiled heating wire. The results showed that the ignition delay time increased with a decrease of the ambient pressure, due to an increased distance between kerosene and oxygen molecules. Steady burning and disruptive burning were identified following the ignition. $\mathrm{OH}^{*}$ chemiluminescence images showed a spherical flame and a longer flame standoff distance under a lower pressure. The puffing intensity was observed to be enhanced with a reduction of the ambient pressure, and a decreased pressure was found to lower the sooting emission.

Keywords: kerosene droplet, ignition, puffing, sooting, sub-atmospheric pressure
\end{abstract}

\footnotetext{
*Corresponding author

Email address: wangzh@zju.edu.cn (Zhihua Wang)
} 


\section{Introduction}

2 A ramjet is an air-breathing high-speed jet engine, which has the advan3 tages of simple structures and high performance [1. For a ramjet, the stable4 performance height is below $20 \mathrm{~km}$. As the flight altitude increases, the ambient 5 pressure at the inlet of the combustion chamber will decrease to 0.1 bar- 0.3 bar, due to a reduced air density. This situation will cause ignition difficulties and reduce the stability of the flame, which significantly affects the combustion efficiency and working performance of aircrafts [2]. Therefore, investigating liquid-fuel combustion mechanisms under low-pressure conditions is essential to improve the stability of the combustor under extreme conditions.

Kerosene is a commonly used fuel for ramjets, owing to its high energy density and stable thermodynamic characteristics [3]. To better understand the combustion characteristics of liquid fuels inside the aero-engine chamber, investigations of fuel droplet combustion is necessary and important [4-6]. A first key performance indicator of droplet burning is ignition. Law [7] investigated effects of droplet heating on the ignition delay, and ignition was found to occur when the Damköhler number of the system exceeded the ignition Damköhler number. Kadota et al. [8] studied the ignition delay of a single-component droplet at high pressure and found that the ignition delay decreased with an increase in the ambient pressure.

In previous studies of a multicomponent fuel droplet, puffing is a common phenomenon observed, characterized as a disruptive burning process 9-11]. It is now well known that puffing is due to the nucleation and growth of bubbles inside the droplet, leading to bursting of the fuel droplet under superheating [12]. It can enhance the internal mixing of the droplet, deform the liquid-air interface and the droplet shape, and cause secondary fragmentation of the droplet 27 [13. The ejection of boiled vapor improves fuel-vapor/air mixing, which in turn 28 improves combustion. Effects of pressure on the occurrence of microexplosion, 29 which is an extremely intense puffing, has been experimentally studied by Wang so et al. [14. Their results show that an elevated pressure advances the time of 
its occurrence. However, the influence of pressure on puffing intensity is not yet well understood.

Another important phenomenon related to kerosene droplet combustion is sooting. As soot formed in a droplet flame is controlled by the evaporation of liquid fuel, it is different from that formed in the combustion of gaseous fuel [15]. Moreover, the majority of the studies focus on soot characteristics of a burning fuel droplet under atmospheric and elevated ambient pressures. Kadota et al. [16 also noted that increasing pressure enlarged the size of soot particles, but did not change their structures at pressures ranging from $0.1 \mathrm{MPa}$ to $3 \mathrm{MPa}$. For a 1-Propanol droplet, Dakka and Shaw [17 also reported a more intense sooting behaviour at $0.3 \mathrm{MPa}$ and above, while soot was not observed at 0.1 $\mathrm{MPa}$.

Although RP-3 kerosene is the most important aviation hydrocarbon fuel in China [18, experimental studies on the combustion characteristics, especially under sub-atmospheric pressure, are inadequate. In this study, high-speed, $\mathrm{OH}^{*}$ chemiluminescence and soot thermal radiation imaging were used to study the ignition, puffing and sooting characteristics of Chinese RP-3 kerosene droplet burning under $0.2-1$ bar. The effects of the ambient pressure on droplet burning are elaborated in several aspects.

\section{Experimental setup}

Fig. 1 shows a schematic of the experimental setup. The experiments were performed in a $0.091 \mathrm{~m}^{3}$ pressure-controlled stainless-steel chamber, which has four quartz windows for optical measurement. Compared to the droplet size, the chamber volume is large enough so that the ambient-gas influence on droplet combustion can be neglected. To support the droplet and simultaneously measure droplet temperature, a $0.1 \mathrm{~mm}$ type-S platinum/platinum-rhodium thermocouple was used. A micro-pipette was used to produce a $1.45 \pm 0.1 \mathrm{~mm}$ fuel droplet and place it on the tip of the thermocouple. The size of the thermocouple is smaller than $10 \%$ of the droplet size, so the thermocouple did not significantly 

hot wire was maintained at about $3.10 \mathrm{~A}$ during the ignition.

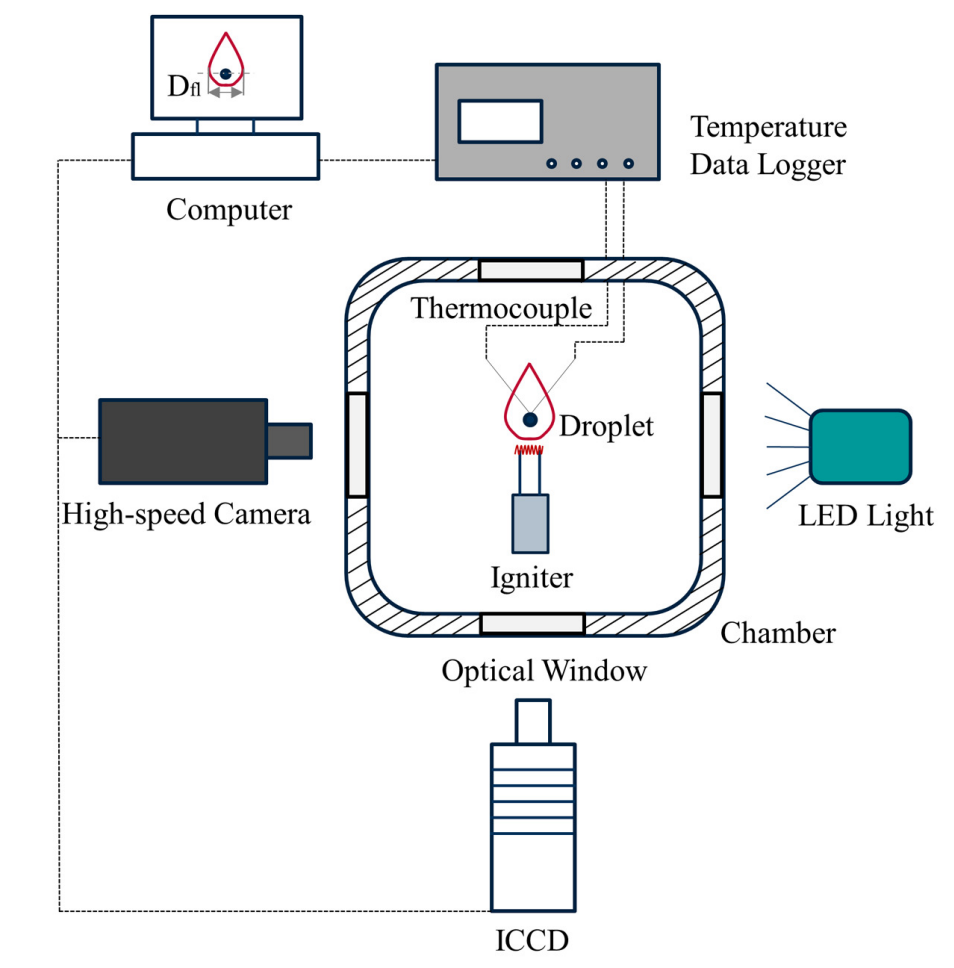

Figure 1: Schematic of experimental setup

influence the burning characteristics during droplet combustion [19]. A coiled hot wire was used for ignition and withdrawn by an air cylinder immediately after an ignition succeeded. The ignition time was precisely controlled by a time-delay relay whose resolution is $0.01 \mathrm{~s}$, and the current flowing through the

The burning history of a fuel droplet was recorded by two cameras. The first one was a black/white high-speed camera (IDT Y4-S1) at 2000 frames/s with an exposure time of $200 \mu \mathrm{s}$ fitted with a Sigma $105 \mathrm{~mm}$ macro lens. To measure the location of the flame front during the combustion, an intensified chargedcoupled device (ICCD, PI-MAX4) camera was used to record $\mathrm{OH}^{*}$ chemiluminescence signals, which was equipped with a Nikon PF10545MF-UV lens and a narrowband interference filter centred at $310 \mathrm{~nm}$. The ICCD equipped with a $652 \mathrm{~nm}$ narrowband filter was used to record the concentration and distri- 
bution information of the burning soot particles 20. An Agilent 3970A data logger was used to collect the temperature inside the droplet at $10 \mathrm{~Hz}$ during the combustion process.

The droplet diameter was evaluated using Matlab. As the droplet was not spherical due to gravity and puffing, the droplet diameter was calculated by $\pi D^{2} / 4=A_{\mathrm{p}}$, where $A_{\mathrm{p}}$ is the projected droplet area on the observing direction.

The maximum uncertainty in droplet diameter measurements is estimated to be $10 \%$ [21].

The fuel used for all the experiments was Chinese RP-3 kerosene. The major components are shown in Tables 1 [22.

Table 1: Major components of Chinese RP-3 kerosene (mass fraction)

\begin{tabular}{cccccccc}
\hline \multicolumn{3}{c}{ Saturated hydrocarbons } & \multicolumn{5}{c}{ Aromatic hydrocarbons } \\
\hline \multirow{2}{*}{ Alkanes } & \multicolumn{3}{c}{ Naphthenes } & Alkyl & Indan \& \\
\cline { 2 - 5 } & Monocyclic & Bicyclic & Tricyclic & Benzenes & Tetralin & Naphthalene & $\begin{array}{c}\text { Naphthalene } \\
\text { derivatives }\end{array}$ \\
\hline 52.2 & 33.8 & 6.0 & 0.1 & 5.1 & 1.3 & 0.6 & 0.9 \\
\hline
\end{tabular}

\section{Results and discussion}

\subsection{Pressure influence on ignition delay}

Once the igniter was moved to the target location which is $1 \mathrm{~mm}$ beneath the droplet, the droplet temperature began to rise, and volatile components of RP-3 on the droplet surface evaporated to form a vapor cloud surrounding the droplet. Ignition was identified by finding a spherical luminous region surrounding the droplet, which exceeded 50\% maximum image intensity. The droplet size slightly increased because of the rise of the droplet temperature.

The ignition delay time is defined as the duration between the time when the igniter reaches the target location and when an ignition succeeds. The pressure influence on the ignition delay time is shown in Fig. 2. The ignition delay time increases as the pressure decreases from 1.0 bar to 0.2 bar. One reason is that the $\mathrm{RP}-3$ and $\mathrm{O}_{2}$ molecule numbers per unit volume decrease with a reduction 


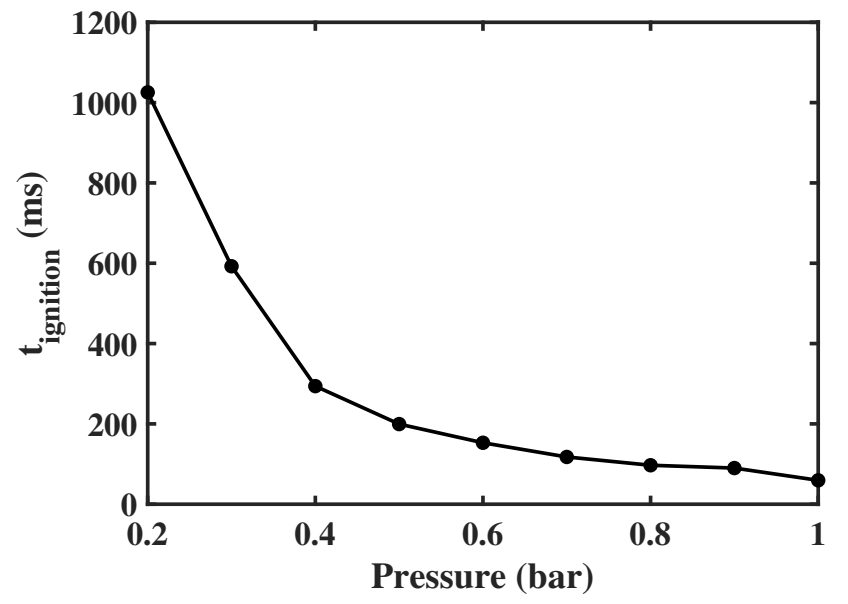

Figure 2: Ignition delay time of RP-3 droplet at different pressures

96 of the ambient pressure. This will result in an increased distance between the $97 \quad \mathrm{RP}-3$ and $\mathrm{O}_{2}$ molecules, thereby reducing the probability of collisions between 98 them.
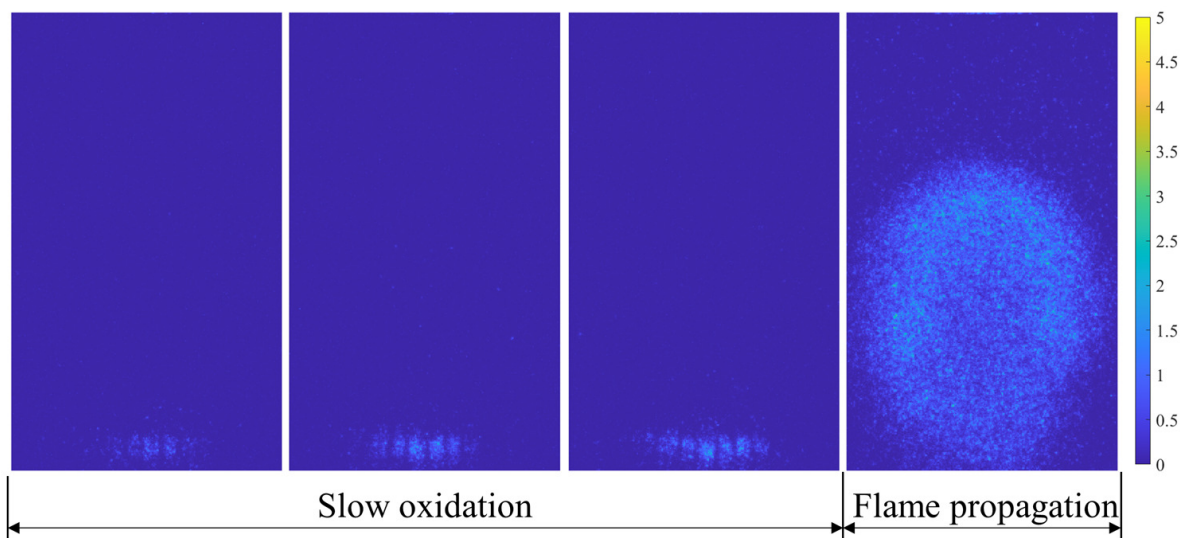

Figure 3: $\mathrm{OH}^{*}$ chemiluminescence during ignition at 0.2 bar

Fig. 3 shows the $\mathrm{OH}^{*}$ chemiluminescence during the ignition at 0.2 bar. It can be seen that the ignition process of the droplet can be divided into two stages. The first stage is the slow oxidation process of RP-3 before the ignition, while in the second stage, an initially premixed flame propagates from the ig- 
nition kernel location and later surrounds the droplet. In the first stage, the RP-3 droplet was heated by the igniter, and the most volatile component began to evaporate and diffuse towards the location of the igniter. The fuel molecules then pyrolyzed and oxidized because of the relatively high local temperature. Among the reactions, the most significant elementary reaction to trigger the ignition is

$$
\mathrm{H}+\mathrm{O}_{2}=\mathrm{OH}+\mathrm{O}
$$

which can generate a large amount of active $\mathrm{OH}^{*}$ radicals to facilitate the ignition of the RP-3 droplet [23].

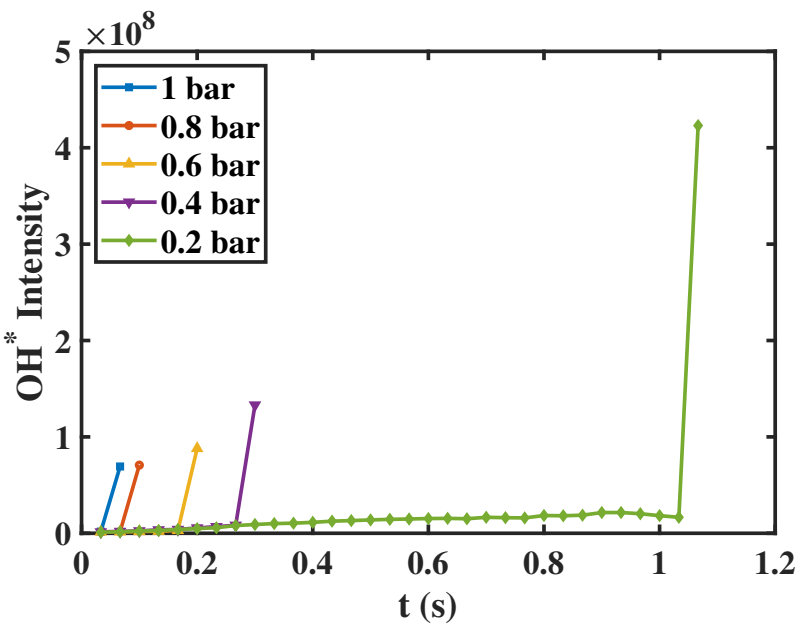

Figure 4: Time evolution of $\mathrm{OH}^{*}$ chemiluminescence intensity at different pressures

Fig. 4 shows the $\mathrm{OH}^{*}$ chemiluminescence intensity during the ignition at different pressures. As the pressure decreases, Reaction (1) needs much more time to trigger the chain reaction of RP-3, because of a larger distance between molecules. After the ignition, the $\mathrm{OH}^{*}$ chemiluminescence intensity is stronger under a lower pressure than that under a higher pressure, because of a larger amount of evaporated RP-3 molecules surrounding the droplet caused by a longer heating time. Another possible explanation for this is that the quenching rate of $\mathrm{OH}^{*}$ chemiluminescence decreased, due to the reduced collisional rate 
between molecules under lower pressure 24 .

\subsection{Pressure influence on burning behaviour}

Following the ignition, the burning behaviour of the RP-3 droplet under different pressures were investigated next. As shown in Figs. 5,7, for all the experiments, the burning of the RP-3 droplet can be divided into two stages: (1) steady combustion; (2) disruptive combustion. Fig. 8 and Fig. 9 compare the size and temperature histories of the droplet at different pressures. During the steady-combustion stage, the droplet temperature rapidly rose until reaching the boiling temperature of the most volatile component of RP-3. An envelope-shape flame formed surrounding the suspended droplet and the flame size increased gradually. According to the $\mathrm{OH}^{*}$ chemiluminescence figures, the droplet burned smoothly without disruptions on the flame front. The luminous yellow region surrounding the droplet indicated the broadband radiant emission from soot [25]. The droplet diameter continued to decrease with time, which approximately agrees with the classical $\mathrm{D}^{2}$ law [26].

Following the steady combustion, the RP-3 droplet displayed puffing behaviour, resulting in disruptive burning. Fig. 10 shows the process of nucleation, multiple bubble formation, growth, merging, and inner circulation, which eventually causes bubble breakup and sub-droplets ejection at 1 bar. Following the steady burning stage, homogeneous nucleation occurred inside the droplet, leading to several small bubbles. Then, bubbles began to grow once their sizes surpassed the critical size, due to the high vapor pressure inside the bubbles and thermal diffusion effects. With inner circulation, all the bubbles eventually merged into one big bubble. Meanwhile, the droplet expanded slightly because of the inner boiling. When the big bubble reached the droplet surface, an ejection of fuel vapor and sub-droplets occurs. The distorted and bright flame region indicates that the local equivalence ratio was enhanced owing to the puffing. Puffing repeated multiple times until the extinction of the droplet.

Since RP-3 kerosene is a multicomponent fuel, more volatile components will evaporate first at the droplet surface, and the surface temperature will 


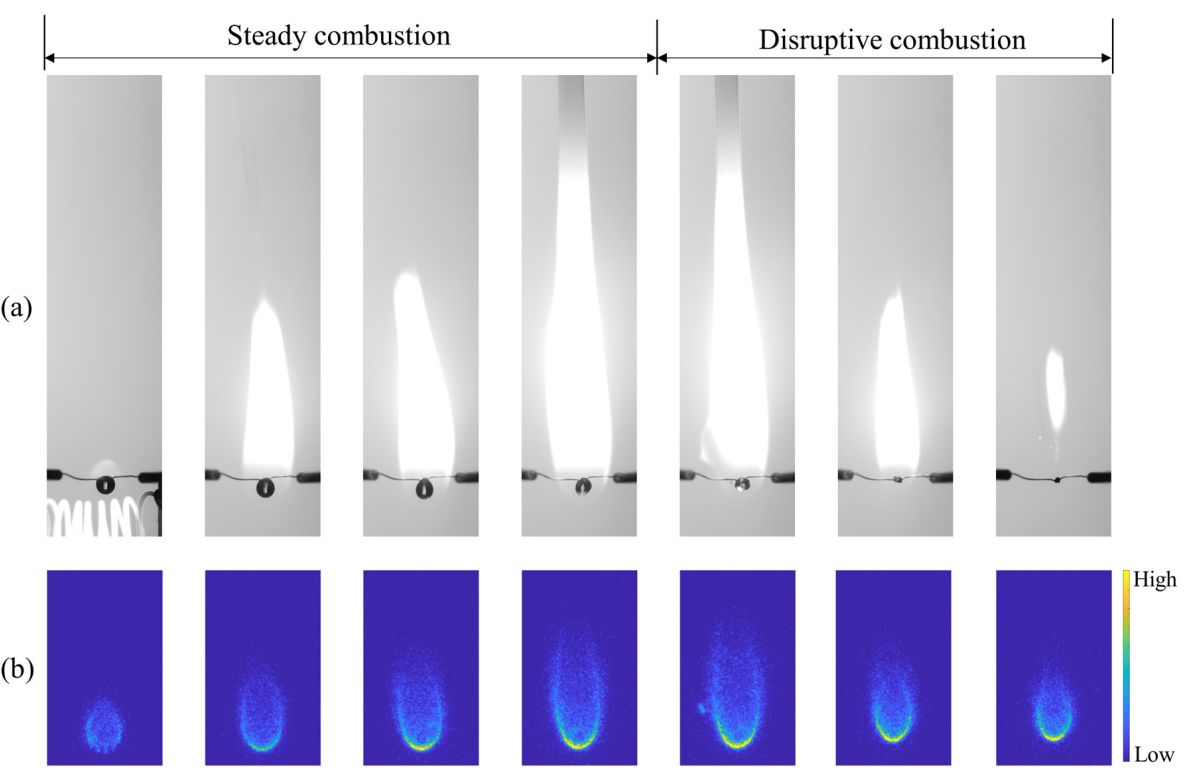

Figure 5: Burning sequences at 1 bar: (a) Images captured by high speed camera; (b) Images of $\mathrm{OH}^{*}$ chemiluminescence emission captured by ICCD equipped with $310 \mathrm{~nm}$ filter

(a)

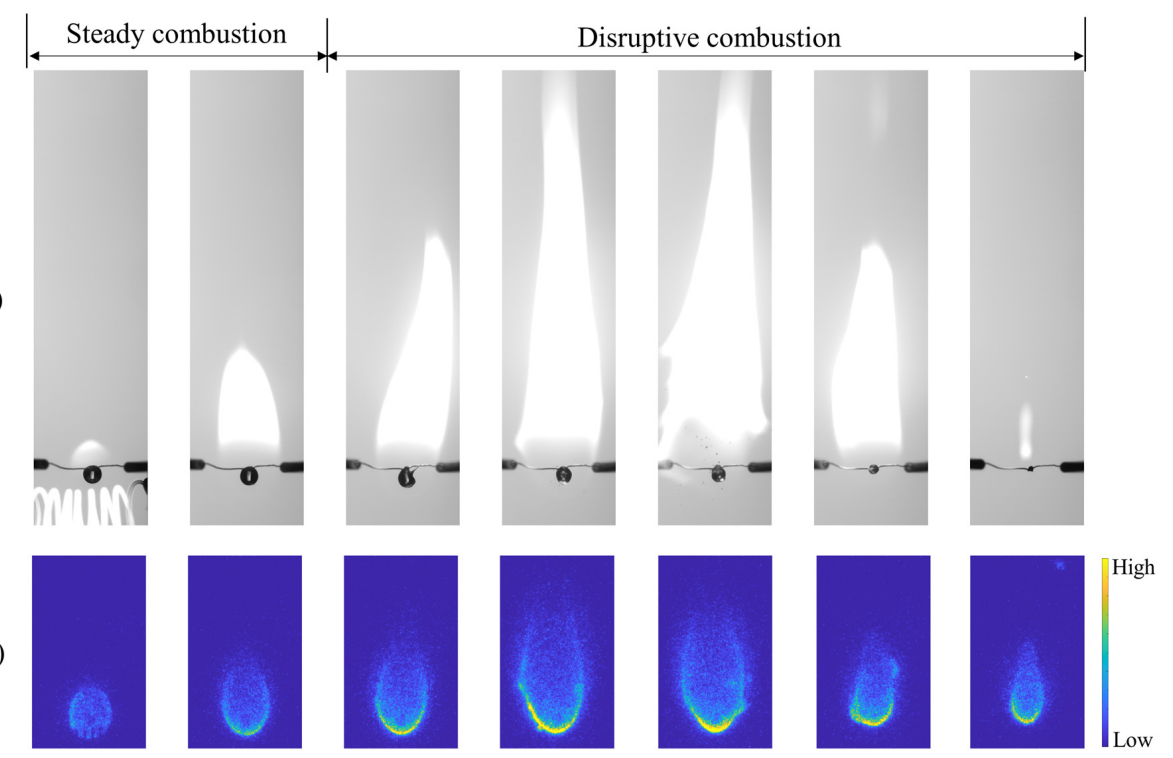

Figure 6: Burning sequences at 0.6 bar: (a) Images captured by high speed camera; (b) Images of $\mathrm{OH}^{*}$ chemiluminescence emission captured by ICCD equipped with $310 \mathrm{~nm}$ filter 
(a)

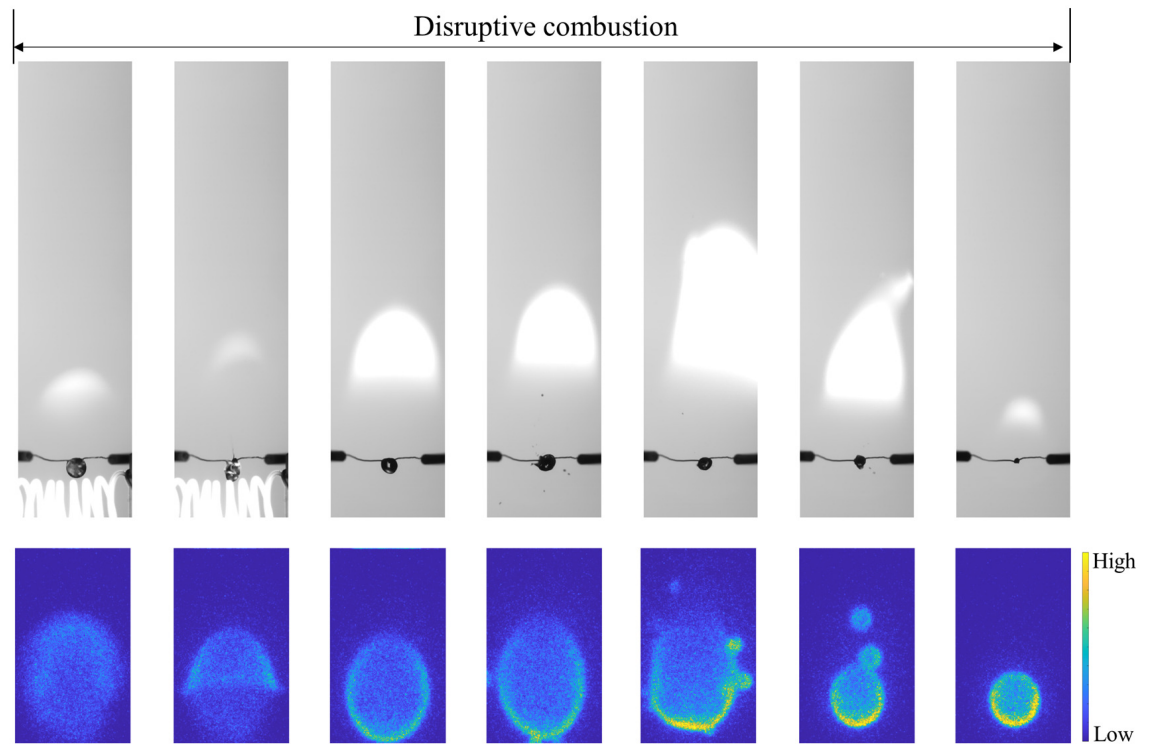

Figure 7: Burning sequences at 0.2 bar: (a) Images captured by high speed camera; (b) Images of $\mathrm{OH}^{*}$ chemiluminescence emission captured by ICCD equipped with $310 \mathrm{~nm}$ filter

be dominated by less volatile components with a higher boiling temperature. Meanwhile, more volatile components remain inside the droplet. Under continuous superheating, the inner-droplet temperature will exceed the superheat limit temperatures of more volatile components. The superheating will cause homogeneous nucleation inside the droplet, which leads to puffing.

Pressure effects on flame structure. When the ambient pressure is 1 bar, the flame shape was distorted from the spherical symmetry because of the buoyancy effect. Due to the natural convection, the downstream region was stretched, while the upstream region was compressed. Considering that the droplet size is relatively large, the natural convection effect became prominent, leading to high flow velocities surrounding the droplets. Since the buoyance effect reduces as the ambient pressure decreases, a less-stretched spherical flame was observed at a lower pressure. And the flame front gradually moved away from the droplet surface at a reduced pressure, which characterized as an increasing trend of the horizontal flame standoff ratio, $D_{\mathrm{fl}} / D$. The horizontal flame standoff ratios for 


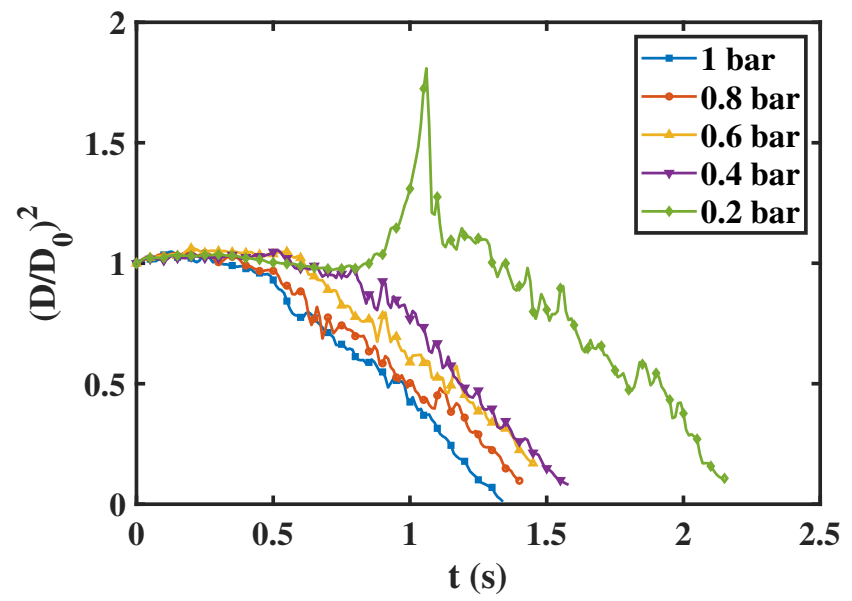

Figure 8: Droplet size histories at different pressures

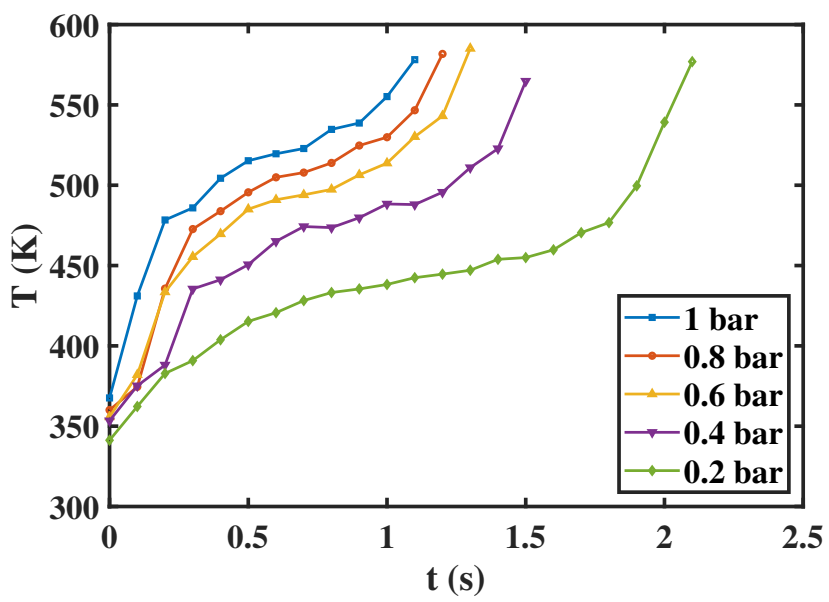

Figure 9: Droplet temperature histories at different pressures

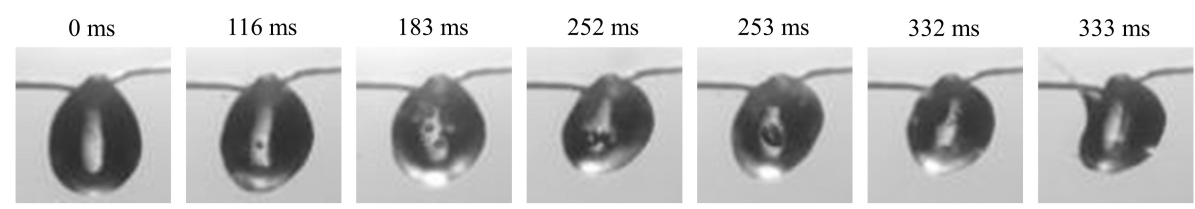

Figure 10: The process of nucleation, bubble growth, merging of bubbles, inner circulation, breakup and eventually sub-droplets ejection at 1 bar 
different pressures are as follows: $\left(D_{\mathrm{fl}} / D\right)_{1 \mathrm{bar}}=2.93 \pm 0.22 ;\left(D_{\mathrm{fl}} / D\right)_{0.6 \mathrm{bar}}=$ $3.91 \pm 0.75 ;\left(D_{\mathrm{fl}} / D\right)_{0.2 \mathrm{bar}}=6.47 \pm 0.65$, where $D_{\mathrm{fl}}$ is measured from $\mathrm{OH}^{*}$ chemiluminescence images.

Pressure effects on droplet temperature. Following the ignition, the droplet temperature first rapidly rose for a period and then slowly increased. During the latter stage, the droplet temperature can be considered to be the same as the pressure-dependent saturation temperature of RP-3 kerosene. As the boiling temperature of the droplet decreases with the reduction of the ambient pressure, the ignition and flame temperatures decreased accordingly. As shown in Fig. 9, the boiling temperatures of RP-3 kerosene are within the ranges of: $478.4 \sim 538.7$ K (1 bar), 472.7 529.9 K (0.8 bar), 469.7 513.7 K (0.6 bar), 435.4 487.9 K (0.4 bar) and 390.8 454.9 K (0.2 bar), respectively.

Pressure effects on puffing. Puffing was observed in all the experiments. As shown in Fig. 8, the oscillations of the droplet size indicate flame disruption due to puffing during the burning. The first puffing for all the cases occurred after the ignition except at 0.2 bar. Due to a longer ignition time and a lower boiling point under the low ambient pressure 0.2 bar, the inner boiling caused ejection of fuel vapor and sub-droplets during the ignition, which facilitated the ignition by enhancing the local equivalence ratio. However, the bubble growth rate is much slower than that during the burning, owing to a lower temperature of the droplet.

Moreover, the intensity of puffing was enhanced with the decrease of the ambient pressure. A much more severe distortion of the flame at sub-atmospheric pressure can be found in Figs. 5,7, which is caused by the ejection of vapor and multiple microdroplets. Meanwhile, the $\mathrm{OH}^{*}$ chemiluminescence due to sub-droplet burning was captured in the figures.

As the intensity of puffing is controlled by the bubble growth process, which can be divided into three stages: (1) Inertia controlled stage, characterized by a rapid growth rate as a result of the difference between the pressure inside the bubble and the ambient pressure; (2) Transition stage, during which the interface velocity is significantly reduced; (3) Diffusion controlled stage, which is 
dominated by thermal diffusion effects, leading to a much slower bubble growth rate. During the inertia controlled stage, the bubble growth process can be modelled as 27:

$$
R(t)=\left[\frac{2}{3} \frac{\rho_{\mathrm{v}}}{\rho_{\mathrm{l}}} A\left(T_{0}-T_{\mathrm{B}}\right)\right]^{1 / 2} \cdot t,
$$

$$
P_{\mathrm{v}}-P_{\infty}=\rho_{\mathrm{v}} A\left(T_{0}-T_{\mathrm{B}}\right),
$$

where $\rho_{\mathrm{v}}$ is the density of the saturated vapor inside the bubble, $\rho_{\mathrm{l}}$ is the density of the liquid, $A$ is a linearization constant, $T_{0}$ is the initial temperature at the bubble boundary, $T_{\mathrm{B}}$ is the saturation temperature of the liquid, $P_{\mathrm{v}}$ is the vapor pressure inside bubble and $P_{\infty}$ is the ambient pressure.

Therefore, $P_{\mathrm{v}}-P_{\infty}$ in Eq.(3) increases with the reduction of the ambient pressure. Consequently, inertia controlled bubble growth will become more effective at a lower pressure, resulting in intense puffing of the droplet.

\subsection{Pressure influence on sooting characteristics}

As the broadband radiant emission from soot is characterized by the luminous yellow region above the droplet, sooty flames were observed in all the experiments following the ignition. The presence of luminous sooty areas can be caused by two factors. On the one hand, the upwardly directed natural convection carries soot particles towards downstream. On the other hand, the oxidation rate of soot particles is finite. Therefore, when soot particles pass through the flame, they are heated and oxidized. The reaction takes a finite time to complete and, therefore, extends above the flames [15]. And the location and dimension of the luminous yellow region is opposite with those of the fuel and oxidizer zone, as shown in Fig. 5,7. As convection intensity increases at high ambient pressure, the opening of the flame rear region and soot particle escape will occur.

As shown in Fig. 11(a) and Fig. 7, with the reduction of the ambient pressure, the yellow luminous zone was observed to gradually stand further away 


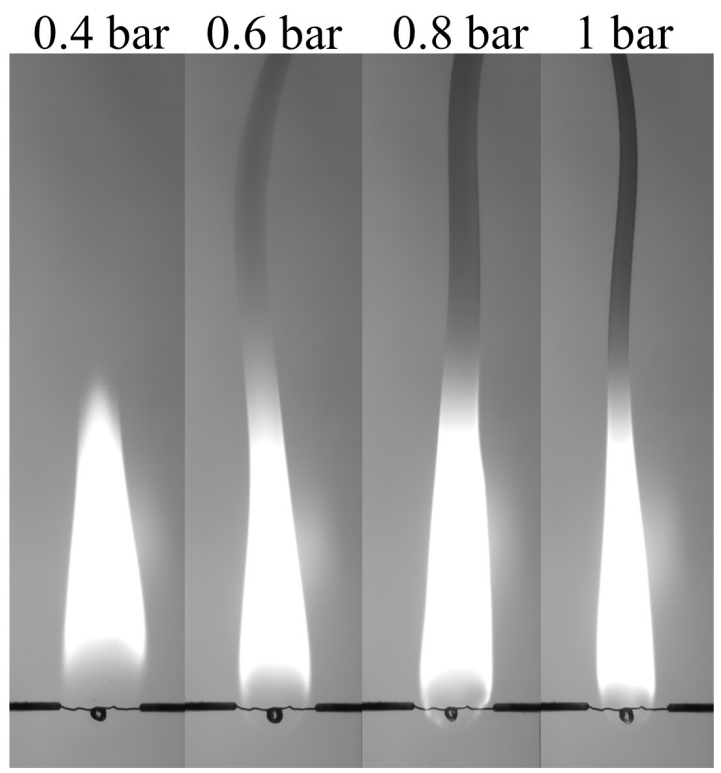

(a)
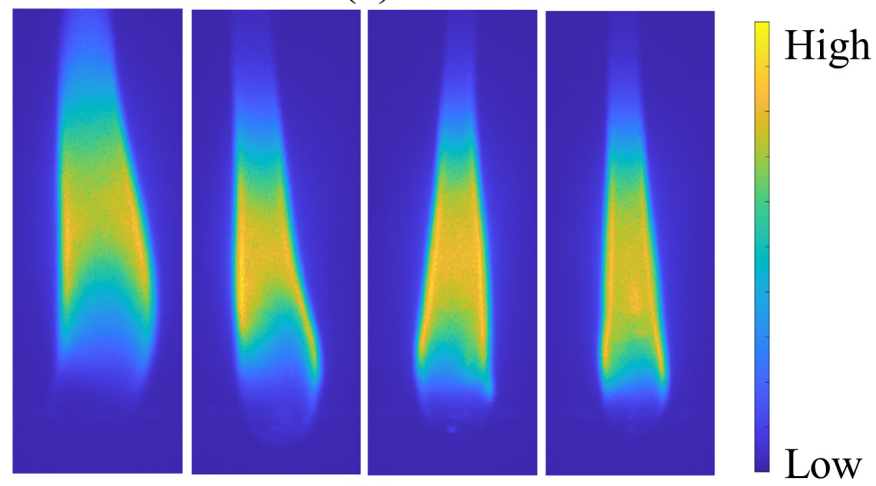

(b)

Figure 11: Sooting characteristics of RP-3 droplet burning at different pressures (a) Images captured by high speed camera; (b) Images of thermal radiation emission of burning soot particles captured by ICCD equipped with $652 \mathrm{~nm}$ filter 
from the droplet surface and expand because of less convection effects. Meanwhile, at 0.4 bar and 0.2 bar, the particles having escaped from the flame tip became invisible. And the particle stream appeared darker and denser under a higher ambient pressure. Fig. 11(b) shows the emission originated from thermal radiation of the burning soot particles, the soot particles were found to be concentrated on the edges of the downstream flow at all pressures, which agreed well with the Laser-induced incandescence (LII) results obtained by Vander Wal et al. 28. And the emission intensity decreased with the reduction of the ambient pressure, as shown in Fig. 12 .

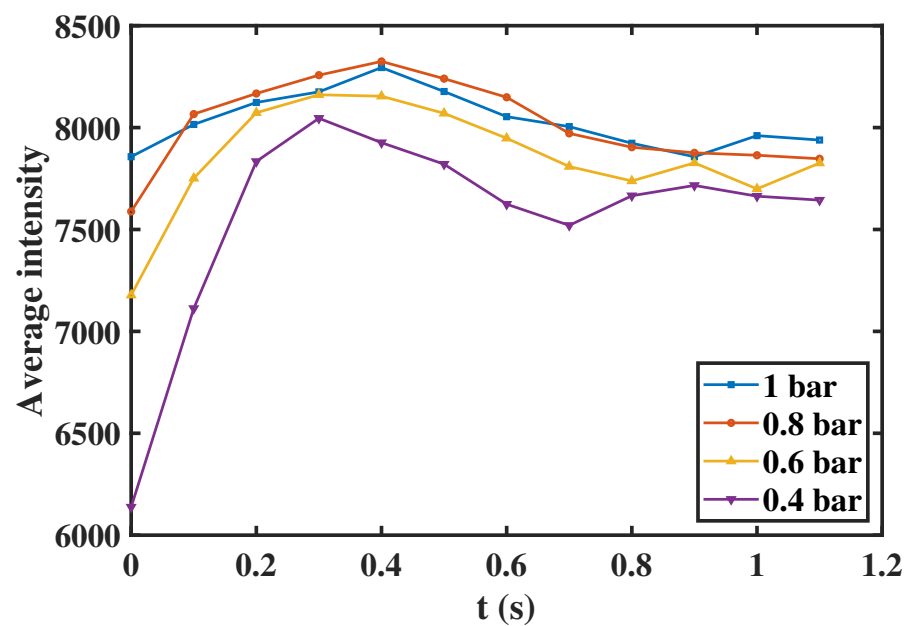

Figure 12: Average emission intensity histories of soot particles thermal radiation at different pressure

The above observations are due to two reasons. First, the distance between molecules increases with the reduction of the pressure, and the probability of collision between small molecules decreases, which makes it difficult to form large molecules. Moreover, due to the weakening of the convection effect at lower pressures, the residence time of soot molecules in the oxidation zone increases, thereby generating less macromolecular polymers. 


\section{Conclusions}

The ignition, combustion and sooting characteristics of a Chinese RP-3 kerosene droplet were investigated and compared under different sub-atmospheric ambient pressures. The following conclusions can be drawn from the present study:

1. The ignition delay time of the droplet increased with the reduction of the ambient pressure (1 bar - 0.2 bar), which is caused by an increased distance between fuel and oxidant molecules. Meanwhile, two distinctive stages were identified for the droplet ignition, i.e. a slow oxidation process followed by propagation of an initially premixed flame. According to the comparison of the $\mathrm{OH}^{*}$ chemiluminescence, an increase of the time for the first stage contributed to a longer ignition delay time under a lower ambient pressure.

2. Following the ignition, the droplet underwent steady and disruptive burning except at 0.2 bar. With the reduction of the ambient pressure, the buoyance effect surrounding the droplet was weakened, resulting in a spherical flame and a larger flame standoff ratio. At the same time, the RP-3 kerosene boiling temperature decreased from $478.4 \sim 538.7 \mathrm{~K}$ at 1 bar to $390.8 \sim 454.9 \mathrm{~K}$ at 0.2 bar.

3. Puffing was observed in all the experiments. The first disruptive ejection occurred in the ignition stage when the ambient pressure dropped to 0.2 bar. The reduction of the pressure enhanced the intensity of puffing because of effective inertia controlled bubble growth at a lower pressure.

4. Under the ambient pressure below 0.4 bar, the particulates having escaped from the rear flame region became invisible, and the average emission intensity originated from thermal radiation of the burning soot particles decreased with the reduction of the ambient pressure, due to an increased distance between molecules and weakened convection effects. 


\section{Acknowledgement}

Financial support from the China Scholarship Council, the National Natural Science Foundation of China (51621005), Fundamental Research Funds for the Central Universities (2020FZZX003-01-01), the Royal Society (IES $\backslash$ R3 $\backslash 193152$ ) and the Engineering and Physical Sciences Research Council (EPSRC; EP/T033940/1) of the UK is gratefully acknowledged.

\section{References}

[1] T. Inamura, M. Takahashi, A. Kumakawa, Combustion characteristics of a liquid-fueled ramjet combustor, J. Propul. Power 17 (4) (2001) 860-868. doi:10.2514/2.5817.

[2] W. L. Luo, Y. Pan, J. G. Tan, Z. G. Wang, Experimental investigation on combustion efficiency of the ramjet model at low pressure, J. Propul. Tech. 31 (3) (2010) 270-275.

[3] P. Dagaut, M. Cathonnet, The ignition, oxidation, and combustion of kerosene: A review of experimental and kinetic modeling, Prog. Energy Combust. Sci. 32 (1) (2006) 48-92. doi:10.1016/j.pecs.2005.10.003

[4] B. H. Chen, J. Z. Liu, H. P. Li, W. J. Yang, K. F. Cen, Laser ignition and combustion characteristics of al/jp-10 nanofluid droplet, J. Therm. Anal. Calorim. 135 (2) (2019) 925-934. doi:10.1007/s10973-018-7393-6

[5] T. I. Farouk, Y. C. Liu, A. J. Savas, C. T. Avedisian, F. L. Dryer, Submillimeter sized methyl butanoate droplet combustion: Microgravity experiments and detailed numerical modeling, Proc. Combust. Inst. 34 (1) (2013) 1609-1616. doi:10.1016/j .proci.2012.07.074.

[6] A. Ambekar, A. Chowdhury, S. Challa, D. Radhakrishna, Droplet combustion studies of hydrocarbon-monopropellant blends, Fuel 115 (2014) 697-705. doi:10.1016/j.fuel.2013.07.056 
[7] C. K. Law, Theory of thermal ignition in fuel droplet burning, Combust. Flame 31 (1978) 285-296. doi:10.1016/0010-2180(78)90141-4.

[8] T. Kadota, H. Hiroyasu, H. Oya, Spontaneous ignition delay of a fuel droplet in high pressure and high temperature gaseous environments, Bull. JSME 19 (130) (1976) 437-445. doi:10.1299/j sme1958.19.437.

[9] J. Shinjo, J. Xia, L. C. Ganippa, A. Megaritis, Physics of puffing and microexplosion of emulsion fuel droplets, Phys. Fluids 26 (10) (2014) 103302. doi:10.1063/1.4897918.

[10] D. C. K. Rao, S. Karmakar, S. K. Som, Puffing and micro-explosion behavior in combustion of butanol/jet a-1 and acetone-butanol-ethanol (a-be)/jet a-1 fuel droplets, Combust. Sci. Technol. 189 (10) (2017) 1796-1812. doi:10.1080/00102202.2017.1333502.

[11] M. L. Botero, Y. Huang, D. L. Zhu, A. Molina, C. K. Law, Synergistic combustion of droplets of ethanol, diesel and biodiesel mixtures, Fuel 94 (2012) 342-347. doi:10.1016/j.fuel.2011.10.049.

[12] M. M. Avulapati, L. C. Ganippa, J. Xia, A. Megaritis, Puffing and microexplosion of diesel-biodiesel-ethanol blends, Fuel 166 (2016) 59-66. doi: 10.1016/j.fuel.2015.10.107.

[13] A. Hoxie, R. Schoo, J. Braden, Microexplosive combustion behavior of blended soybean oil and butanol droplets, Fuel 120 (2014) 22-29. doi: 10.1016/j.fuel.2013.11.036.

[14] C. H. Wang, X. Q. Liu, C. K. Law, Combustion and microexplosion of freely falling multicomponent droplets, Combust. Flame 56 (2) (1984) 175-197. doi:10.1016/0010-2180(84)90036-1.

[15] A. L. Randolph, C. K. Law, Influence of physical mechanisms on soot formation and destruction in droplet burning, Combust. Flame 64 (3) (1986) 267-284. doi:10.1016/0010-2180(86)90145-8. 
[16] T. Kadota, H. Hiroyasu, A. Farazandehmehr, Soot formation by combustion of a fuel droplet in high pressure gaseous environments, Combust. Flame 29 (1977) 67-77. doi:10.1016/0010-2180(77)90094-3

[17] S. M. Dakka, B. D. Shaw, Influences of pressure on reduced-gravity combustion of 1-propanol droplets, Microgravity Sci. Tec. 18 (2) (2006) 5-13. doi:10.1007/BF02870978.

[18] Y. Liu, Y. Liu, D. Chen, W. Fang, J. Li, Y. Yan, A simplified mechanistic model of three-component surrogate fuels for rp-3 aviation kerosene, Energy Fuels 32 (9) (2018) 9949-9960. doi:10.1021/acs.energyfuels.8b02094

[19] E. Mura, R. Calabria, V. Califano, P. Massoli, J. Bellettre, Emulsion droplet micro-explosion: Analysis of two experimental approaches, Exp. Therm. Fluid Sci. 56 (2014) 69-74. doi:10.1016/j.expthermflusci. 2013.11 .020

[20] W. Weng, M. Costa, Z. Li, M. Aldén, Temporally and spectrally resolved images of single burning pulverized wheat straw particles, Fuel 224 (2018) 434-441. doi:10.1016/j.fuel.2018.03.101

[21] D. L. Dietrich, P. M. Struk, M. Ikegami, G. Xu, Single droplet combustion of decane in microgravity: experiments and numerical modelling, Combust. Theory Model. 9 (4) (2005) 569-585. doi:10.1080/13647830500256039.

[22] W. Zeng, H. Li, B. Chen, H. Ma, Experimental and kinetic modeling study of ignition characteristics of chinese rp-3 kerosene, Combust. Sci. Technol. 187 (3) (2015) 396-409. doi:10.1080/00102202.2014.948620.

[23] B. H. Chen, J. Z. Liu, F. Yao, Y. He, W. J. Yang, Ignition delay characteristics of rp-3 under ultra-low pressure (0.01-0.1 mpa), Combust. Flame 210 (2019) 126-133. doi:10.1016/j.combustflame.2019.08.009.

[24] M. Tamura, P. A. Berg, J. E. Harrington, J. Luque, J. B. Jeffries, G. P. Smith, D. R. Crosley, Collisional quenching of ch(a), oh(a), and no(a) in 
$343 \quad$ low pressure hydrocarbon flames, Combust. Flame 114 (3) (1998) 502-514.

344 doi:10.1016/S0010-2180(97)00324-6.

[25] J. B. Wei, B. D. Shaw, Reduced gravity combustion of propanol droplets in oxygen-inert environments, Combust. Sci. Technol. 181 (12) (2009) 14801494. doi:10.1080/00102200903190851.

[26] C. K. Law, H. K. Law, A d2-law for multicomponent droplet vaporization and combustion, AIAA J. 20 (4) (1982) 522-527. doi:10.2514/3.51103.

[27] J. C. Lasheas, L. T. Yap, F. L. Dryer, Effect of the ambient pressure on the explosive burning of emulsified and multicomponent fuel droplets, Symp. (Int.) Combust. 20 (1) (1985) 1761-1772. doi:10.1016/S0082-0784(85) 80673-1.

[28] R. L. Vander Wal, D. L. Dietrich, Laser-induced incandescence applied to droplet combustion, Appl. Opt. 34 (6) (1995) 1103-1107. doi:10.1364/ A0.34.001103 